We are interested in learning about student experience with high school science fair. Even if you haven't done science fair, we would like to know about your general impressions concerning what help it would be reasonable for students to receive when doing science fair projects and what obstacles students might face. This survey, which consists of up to about 20 questions, is anonymous and should only require about 10 minutes to complete. We only are interested in overall trends. You may leave blank any question you prefer not to answer. It is important that you give honest replies to those questions that you do answer since the results may be used to influence science fair practices in the future. Your participation in the survey is voluntary; however, the more students who participate in the survey, the more statistically persuasive will be any conclusions.

\section{I am a UTSW}

\section{Gender?}

3. When you were in high school, did you carry out a science fair project?

4. Was carrying out a science fair project possible at your high school?

5. What was the reason that you did not carry out a science fair project?

Check all that apply.
MD Student
$\bigcirc$ MD-PhD Student
$\bigcirc \mathrm{PhD}$ Student
Female
Male
Yes
No
I am unfamiliar with science fair
$\bigcirc$ Yes

$\square$ 1. Not interested
$\square$ 2. Not enough time
$\square$ 3. Too expensive
$\square$ 4. Not enough help available
$\square$ 5. Did not have a good idea for a project
$\square$ 6. Did not want to compete
$\square$ 7. Other

Specify:

4. If you carried out science fair in high school, then what was the highest grade in which you did so?

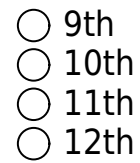

Y Yes

No

4a. Did you carry out science fair more than once?

If you carried out science fair more than once, then on subsequent questions use your most recent experience to answer.

5. Was your science fair project Team or Individual?

$\bigcirc$ Team

Individual

6. Was the science fair project required by your

Yes school?

No

$\bigcirc$ No, but I did a science fair project to satisfy a school project requirement.

7. Do you think science fair projects should be optional or required? (This need not be for

Optional competition.)

Required

8. Reason why?

9. Do you think science fair projects for competition should be optional or required?

Optional

Required 
10. Reason why?

11. From whom do you think it would be reasonable to receive help on a science fair project?

Check all that apply

Specify:

12. Who actually helped you?

Check all that apply

Specify:

13. What kind of help on a science fair project do you think would be reasonable to expect from others? Check all that apply

\section{Specify?}

14. What kind of help did you actually receive? Check all that apply

Specify:

15. Did you get the kind of help you wanted from teachers?
1. Parents

2. Siblings

3. Other family members (uncles, cousins, etc.)

4. Teachers

5. Other students

6. Scientists

7. A paid mentor

8. Articles on the Internet

9. Articles in books or magazines

Other

1. Parents

2. Siblings

3. Other family members (uncles, cousins, etc.)

4. Teachers

5. Other students

6. Scientists

7. A paid mentor

8. Articles on the Internet

9. Articles in books or magazines

Other

1. Being given the main idea

2. Development of the idea

3. Gathering background research information, or finding a research site or participants

4. Performing the experiments

5. Writing the report

6. Fine tuning the report after it is written

7. Designing the poster board and presentation

8. Producing charts or graphs

9. Coaching for the interview with judges

10. Copying the project from someone else

Other

1. Being given the main idea

2. Development of the idea

3. Gathering background research information, or finding a research site or participants

4. Performing the experiments

5. Writing the report

6. Fine tuning the report after it is written

7. Designing the poster board and presentation

8. Producing charts or graphs

9. Coaching for the interview with judges

10. Copying the project from someone else

Other 
16. Was there some kind of help that you would have liked but did not receive?

Specify:

17. Did you get the amount of help you wanted from teachers?

$\bigcirc$ Yes

No

18. Were the results of your project as expected?

$\bigcirc$ Yes

No

19. What obstacles did you face?

Check all that apply

$\square$ 1. Coming up with the main idea

2. Getting motivated to do the project

$\square$ 3. Becoming disappointed with the project

$\square$ 4. Limited resources

5. Limited knowledge

$\square$ 6. Limited skills

$\square$ 7. Limited cooperation

$\square$ 8. Getting organized

9. Time pressure

10. Not enough money

11. Results not as expected

Other

\section{Specify?}

19. What obstacles do you think students who do science fair usually face?

Check all that apply

\section{Specify?}

20. How did you overcome the obstacles you encountered?

Check all that apply

1. Used someone else's main idea

2. Picked a familiar/interesting topic

3. Did more background research

4. Stopped working on the project for a while

5. Made a timeline to follow

6. Perseverance and self-discipline

7. Had someone else to keep me on track

8. Had someone else do the math

9. Changed the research plan

10. Collected more data

11. Had someone else collect the data

12. Used someone else's data

13. Made up the data

14. Changed the hypothesis to fit the data

15. Changed the data to fit the hypothesis

Other

Specify? 
20. How do you think students who do science fair usually overcome obstacles?

Check all that apply
1. Use someone else's main idea

2. Pick a familiar/interesting topic

3. Do more background research

4. Stop working on the project for a while

5. Make a timeline to follow

6. Perseverance and self-discipline

7. Have someone else to keep them on track

8. Have someone else do the math

9. Change the research plan

10. Collect more data

11. Have someone else collect the data

12. Use someone else's data

13. Make up the data

14. Change the hypothesis to fit the data

15. Change the data to fit the hypothesis Other

Specify? 